\title{
Understanding Immersive Research Experiences that Build Community, Equity, and Inclusion
}

\author{
Audrey Rorrer \\ Computer Science \\ UNC Charlotte \\ Charlotte, NC, USA \\ audrey.rorrer@uncc.edu
Sepi Hejazi Moghadam
Google Research
Google
Mountain View, CA, USA
shmoghadam@google.com

\author{
Breauna Spencer \\ Sociology \\ UC Irvine \\ Irvine, CA, USA \\ bspencer@uci.edu \\ Deborah Holmes
Education Evaluation
UNC Charlotte
Charlotte, NC, USA
daholmes@uncc.edu
}

\author{
Sloan Davis \\ Google Research \\ Google \\ Mountain View, CA, USA \\ sloandavis@google.com \\ Cori Grainger \\ Google Research \\ Google \\ Mountain View, CA, USA \\ corigrainger@google.com
}

\begin{abstract}
In this experience report, we describe the rationale and need for immersive research experiences (IREs) in computer science (CS) that are designed to foster an inclusive community that encourages pursuit of graduate education for undergraduate women. Google's exploreCSR supports institutions across the US to execute IREs in computing throughout the academic year. We describe the program design and framework, the evaluation model, and present outcomes from two years of implementation across 29 institutions, with $1,983 \quad(92 \%$ female $)$ student participants collectively. The unique features of the program are that it aligns goals, measurements, and best practices across a national network of hands-on, localized IREs, resulting in peer communities and a sizable sample of undergraduates who identify as women and/or African-American/Black, American Indian/Alaska Native/Native American, Hispanic/Latinx, and/or Native Hawaiian/Pacific Islander (AAHN). We discuss recommendations for effective IRE programming based on our evaluation and the features found to be particularly salient for AAHN women. The contribution of this work is in describing how a national initiative for IREs builds community and creates conditions known to support persistence of women in computer science.
\end{abstract}

\section{CCS CONCEPTS}

- Learning Environment • Undergraduate Research • MixedMethods • Experience Report

Permission to make digital or hard copies of part or all of this work for personal or classroom use is granted without fee provided that copies are not made or distributed for profit or commercial advantage and that copies bear this notice and the full citation on the first page. Copyrights for components of this work owned by others than ACM must be honored. Abstracting with credit is permitted. To copy otherwise, or republish, to post on servers or to redistribute to lists, requires prior specific permission and/or a fee. Request permissions from Permissions@acm.org. SIGCSE'21, March 13-20, 2021, Virtual Event, USA

(C)2021 Association for Computer Machinery.

ACM ISBN 978-1-4503-8062-1/21/03..\$15.00

https://doi.org/10.1145/3408877.3432523

\section{KEYWORDS}

Broadening Participation in Computing, Gender and Diversity, Interactive Learning Environments, Teamwork and Collaboration, Evaluation Model

\section{ACM Reference format:}

Audrey Rorrer, Breauna Spencer, Sloan Davis, Sepi Hejazi Moghadam, Deborah Holmes, \& Cori Grainger. 2021. Understanding Immersive Research Experiences that Build Community, Equity, and Inclusion. In Proceedings of $52^{\text {nd }}$ Technical Symposium on Computer Science Education (SIGCSE'21), March 13-20, Virtual Event, USA, ACM, New York, NY, USA. 7 pages. https://doi.org/10.1145/3408877.3432523

\section{Introduction}

Despite the national increase in computer science (CS) enrollments in recent years, the gender distribution is far from achieving parity $[35,4]$. The ongoing gender disparity is worse for women who identify as African-American/Black, American Indian/Alaska Native/Native American, Hispanic/Latinx, and/or Native Hawaiian/Pacific Islander (AAHN). i.e. Asian, Black, Hispanic/Latinx, Indigenous. The importance of having gender and ethnic parity in CS has been well documented $[10,15,16]$ to ensure that all demographics are part of the design, development, and discovery that shapes our world.

The ecosystem that supports women in CS career pathways is vigorous, with national efforts such as the Computing Research Association-Widening Participation committee, the National Center for Women and Information Technology, and others. Yet, few women choose CS research and academic careers. The 2019 Taulbee Survey [35] reports that just $20 \%$ of CS doctoral degrees were awarded to women, with a decrease in doctoral enrollment and graduations for women identifying as AAHN to 3\%. Unless we change the current trajectory of women in CS pathways, it is predicted that faculty gender parity won't be attained until 2075 [33]. Google's exploreCSR program, hereafter referred to as the Program, provides a unique 
contribution to this ecosystem by supporting a national network of immersive research experiences (IREs) and evaluating their core components most effective for sustaining women, particularly those who identify as AAHN, in CS research specifically.

Undergraduate research programs have been shown to be generally effective recruiting and retention tools [12, 22]. Many CS undergraduate research programs share similar goals of training and preparing students for graduate research [15]. Recruiting and retaining students from diverse backgrounds is a noted focus of undergraduate research programs, such as those sponsored by the National Science Foundation and the Computing Research Association [2]. These efforts are showing positive outcomes, such as gains in technical skills, professional identity, and self-efficacy $[18,26]$. While the enrollment and degree attainment has increased slightly in recent years, the percentage of women enrolling in and obtaining doctoral degrees in CS remains extremely low. In 2019, just 23\% of all CS doctoral students identified as women, $2 \%$ of those women identified as African-American/Black, $2 \%$ as Hispanic/Latinx, and $.23 \%$ as American Indian/Alaska Native/Native American or Native Hawaiian/Pacific Islander [35]. Twenty-one percent of CS doctoral degree recipients were women, among them, $1 \%$ were Black, 1\% Hispanic/Latinx, and 13\% Asian [35].

There are distinct features found to attract and retain women in CS research. Effective retention strategies include providing information about the graduate school experience, discussing gender-relevant topics, applying CS research to social good [10, 31], and participation in technical and professional conferences [32]. Sense of belonging, which is essential for the persistence of women in scientific fields [13] and in CS [5], is fostered through mentoring among women [10], and through creating scaffolded research experiences that are hands-on [3, 10]. For women graduate students, mindset has been found to be especially relevant, as is the opportunity to participate in mentoring undergraduate students [29]. Unfortunately, many AAHN women enrolled in CS degree programs characterize the discipline as discriminatory, because their identities must be pushed aside to focus on CS. This feature diminishes the sense of belonging, fostering isolation [17, 27, 28].

AAHN women experience complexity that is intertwined with having intersectional identities [19]. Many feel isolated in CS academic environments [7], and lack access to technology [19]. Pertinent factors shown to aid in persistence of AAHN women include personal mentoring and research for social activism [9].

Additionally, women of all racial and ethnic backgrounds who struggle with poverty and/or come from a lower socioeconomic background lack resources to engage in research and do not have the 'science capital' to pursue CS research pathways. Science capital, derived from the K-12 education research community [1], refers to social, economic, and cultural factors that influence student career attitudes and choice. Without being able to see and learn from researchers like themselves, students are not able to envision themselves as researchers. Students who are in marginalized gender, racial and ethnic groups are less likely to be afforded research opportunities [32]. Women, and especially AAHN women, face obstacles to pursuing CS research due to the 'paradox of meritocracy' [6], which is linked to the bias of privilege [20]. Without knowing CS researchers, women are not recommended for competitive research opportunities and are less likely to view themselves as scientists [32].

The Program is designed to mitigate these known challenges in CS research for undergraduate women by supporting institutions to successfully execute IREs. The IREs enable women to explore CS research, are open to undergraduate students of all levels and preparation, and are locally available. Each IRE offers a large cohort of women across peer groups, graduate students, and faculty.

\section{Program Design}

exploreCSR aims to increase the number of students who identify as AAHN and/or women pursuing graduate studies and research careers in CS. The Program provides funding, evaluation, and a community of practice to faculty who design and execute research-focused workshops throughout the academic year that expose undergraduates who identify as AAHN and/or women to CS research methodologies, career pathways, and exploratory problems. Faculty propose workshop designs customized to the needs of local students, while aligning to the Program goals and best practices for broadening participation through initiatives like IREs. Twenty-four universities in North America were funded for the 2019-20 academic year, with 14 able to implement workshops and 10 postponing due to COVID-19. The institutions that completed IREs reached 880 students, $75 \%$ of whom identified as women. The pilot year of 2018-19 sponsored workshops across 15 universities, with more than 1,100 student participants, $83 \%$ of whom identified as women (totaling 29 institutions and 1,983 students across both academic years).

The Program combines undergraduate research and collaborative learning [11]. These high-impact practices are known to engage undergraduate students from all backgrounds and to increase their degree persistence. It also includes sustained longer term engagement over time which has been shown to produce better student outcomes [14]. The Program design was modeled on two initiatives [16, 23] to support scaling across institutions with a common alignment of goals, measurements, and best practices. Our Program supports a network of immersive research cohort experiences that create an environment conducive for skill development and confidence building, and generates conditions which have been specifically shown to benefit women generally, as well as AAHN women and low socioeconomic status (SES) students. While each institution customizes their IRE to the local capacity of faculty and needs of students, workshop structures follow one of three standardized delivery modalities. Weekend workshops $(n=16)$ provide structured activities via deep immersion over an entire weekend. Term-long workshops $(n=3)$ engage participants in research at key intervals throughout a semester. Some 
workshops last throughout the academic year $(n=10)$. Each modality provides hands-on research projects to groups of undergraduate women with tiered mentoring, including peer, graduate student, and faculty mentoring. Adaptations include the research topics (e.g., AI, HCI, Robotics) and size and makeup (e.g., presence of faculty and/or graduate student mentor) of collaborative teams.

Programmatic features common to all workshops include topical sessions specifically designed to benefit women. The range of research topics follows the areas of the faculty at awarded institutions, with technical research topics offered at every workshop as a primary method of introducing students to research avenues and techniques. Additionally, all workshops provided speakers and panels on the graduate school experience, how to apply to and fund graduate school, and discussions of career experiences. Topics pertaining to well-being, such as imposter syndrome, growth mindset, and work/life balance, were offered at the majority of the workshops. Through these activities, each of the workshops provides undergraduate women with a large and welcoming community to enhance their experiences in CS research.

Traditional avenues for undergraduate research opportunities are commonly offered as summer programs or academic courses in a term. Summer programs in CS typically have student cohorts of about 10 students from different colleges and universities, few of whom are women [26], and none of whom are part of the students' home institution. Academic courses include the same institutional demographics which lack in gender or ethnic parity [35]. These traditional options lend themselves to isolation for women, and more so for AAHN women. The Program is innovative in its accessibility to undergraduate women, cohort sizes and compositions, and in its provision of a national, high-volume sample size. IREs supported by exploreCSR are accessible to undergraduate students who are interested in exploring research, and not based upon merit- or accomplishment-based competition to apply. It supports immersive research engagement in large cohorts of women, both peers and faculty, local to students' home institutions and contexts. Across both program years, exploreCSR workshops had a mean size of 72 students (median of 57), with a higher percentage of students identifying as AAHN and/or women than comparable initiatives, increasing and enhancing the sense of a community of women. Finally, the Program has a unique visibility into a high number of student experiences across workshop sites from which we draw the subsequent conclusions.

\section{Program Evaluation Model}

The Program goals function as the core evaluation criteria, listed in Figure 1, with the prominent focus being on undergraduate student outcomes.

These criteria are applied to the program evaluation, which encompasses the Results Evaluation model [8] to determine program efficacy in relation to stated goals. Additionally, the CIPP Model [30] provides the evaluation framework, wherein the context, inputs, process, and products are investigated across program stakeholders. Principles of Utilization Focused evaluation [21] are applied to the framework so that meaningful evaluation findings are communicated across stakeholders for program enhancement. The framework is shown in Figure 2.

\begin{tabular}{ll} 
Community & \multicolumn{1}{l}{$\begin{array}{l}\text { Foster a sense of community and support from peer } \\
\text { groups, near-peer \& faculty }\end{array}$} \\
\cline { 2 - 2 } Skills & $\begin{array}{l}\text { Provide practical skills and know-how to help } \\
\text { women succeed in undergraduate programs and } \\
\text { beyond }\end{array}$ \\
\cline { 2 - 2 } Confidence & $\begin{array}{l}\text { Instill confidence that comes from knowing women } \\
\text { have skills to contribute to problem solving beyond } \\
\text { the classroom }\end{array}$ \\
\cline { 2 - 2 } Motivation & $\begin{array}{l}\text { Motivate, inspire and challenge women through } \\
\text { exposure to real-world research problems in } \\
\text { computer science }\end{array}$ \\
\hline
\end{tabular}

Figure 1: Student-focused Program Evaluation Criteria

The overarching evaluation question for the program is: what value does The Program bring to the CS research pipeline efforts? Additional evaluation questions include: Does The Program collectively, and by institution, achieve the stated program goals; What are the long-term impacts of The Program on the CS research pipeline; and How do institutional workshops collaborate, share, and continue effective practices? These questions include leading and lagging indicators, therefore the logic model and corresponding metrics for evidence-based decision making are obtained through a variety of measures over time.

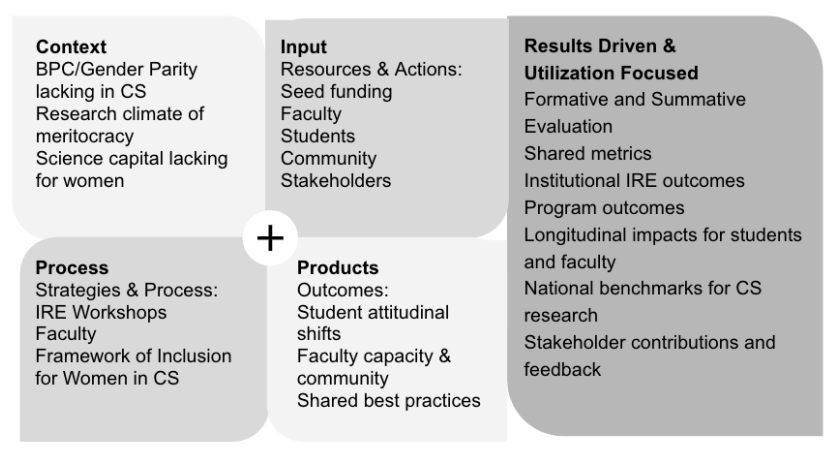

Figure 2: The exploreCSR Evaluation Framework

Figure 3 provides the logic model and key metrics guiding the program evaluation. To address the criteria and the overall evaluative questions, a mixed-methods approach was used to evaluate each institution's workshop, and the aggregate outcomes across the Program. Each institution received a detailed report of their respective workshop outcomes. These reports included a data package of survey results, interview themes, and a narrative report summarizing the summative workshop outcomes. 


\begin{tabular}{|c|c|c|}
\hline Goals & Activities & Shared Metrics \\
\hline $\begin{array}{l}\text { Build Community } \\
\text { Develop Skills } \\
\text { Enhance Confidence } \\
\text { Catalyze Motivation } \\
\text { Share Best IRE Practices }\end{array}$ & $\begin{array}{l}\text { IREs across variety of institutions } \\
\text { Provide peer, near-peer, faculty } \\
\text { mentoring } \\
\text { Faculty Cohort strategy meetings }\end{array}$ & $\begin{array}{l}\text { Participant Tracking by Cohort: } \\
\text { undergraduate, graduate, } \\
\text { faculty partnerships } \\
\text { National benchmarks of } \\
\text { women in CS research } \\
\text { (Taulbee, Workforce) }\end{array}$ \\
\hline Data Collection & Outcomes & Impact \\
\hline $\begin{array}{l}\text { Registration tracking } \\
\text { Pre/Post Student Survey } \\
\text { Interviews } \\
\text { Longitudinal Follow Up Polls } \\
\text { Stakeholder Meetings } \\
\text { IRE Workshop Reports } \\
\text { Summative Evaluation }\end{array}$ & $\begin{array}{l}\text { Students: feel belonging, increase } \\
\text { confidence, skills, awareness \& } \\
\text { preparation for CS research } \\
\text { careers } \\
\text { Faculty: develop community of } \\
\text { practice for inclusion \& equity in } \\
\text { CS research }\end{array}$ & $\begin{array}{l}\text { Increased pipeline of women in } \\
\text { CS graduate programs } \\
\text { Increase of women in CS } \\
\text { research careers } \\
\text { Institutional capacity for IREs }\end{array}$ \\
\hline
\end{tabular}

Figure 3. The exploreCSR Logic Model

The quantitative and qualitative methods are described next. Evaluation results are highlighted in support of the discussion of what went well and what has been learned from formative and summative program evaluation.

\section{Survey Measurement Overview}

Pre- and post-surveys timed to coincide with the start and conclusion of each workshop were conducted across all workshops and institutions for student participants. The adapted survey instrument [25] measured self-efficacy, graduate school interest, attitudes about CS, research skills, and professional identity. Mentoring and program evaluation were included at post-survey. A sense of belonging scale was added to the 2019 instrument following its pilot in the inaugural program year. All items were rated on a 5-point Likert type scale, with 5 being the most positive rating. Independent sample t-tests were performed to measure changes in constructs between pre- and post-survey collection for each cohort year, for the aggregate program and the individual workshops. Additional analyses were performed to address research questions, such as program outcomes by workshop features (e.g. length, topics, etc.) and student intersectional identities (e.g. race/ethnicity, level in school, SES, etc.), which were beyond the scope of this experience report.

In 2019-20, there were 532 survey participants across 14 institutions (response rate of $61 \%$ ), $61 \%$ of whom identified as women, and $38 \%$ of whom identified as AAHN women. Fortyone percent indicated being from low $\mathrm{SES}^{1}$, and $30 \%$ were in their freshman or sophomore years. In 2018-19, there were 525 survey participants across 15 institutions, $87 \%$ of whom identified as women and $36 \%$ of whom identified as AAHN women. Twenty-one percent indicated they were from low socioeconomic backgrounds, and $38 \%$ were in their freshmen or sophomore years.

\footnotetext{
${ }^{1}$ A measure of SES was adopted from Operario, Adler, and Williams (2004). Subjective Social Status: Reliability and Predictive Utility for Global Health. Psychology and Health, April 2004 (19) No. 2, pp 237-246.
}

Table 1. Pre/Post Survey Findings by Cohort

\begin{tabular}{|l|c|c|c|c|}
\hline \multirow{2}{*}{$\begin{array}{l}\text { Construct } \\
\text { Response Rate }\end{array}$} & \multicolumn{2}{|c|}{$\begin{array}{c}\text { 2019-20 Cohort } \\
\mathrm{N}=\mathbf{8 8 0}\end{array}$} & \multicolumn{2}{c|}{$\begin{array}{c}\text { 2018-19 Cohort } \\
\mathrm{N}=1103\end{array}$} \\
\cline { 2 - 5 } & $\begin{array}{c}\text { Pre }(\mathbf{n}=532) \\
\mathbf{6 1 \%}\end{array}$ & $\begin{array}{c}\text { Post }(n=462) \\
53 \%\end{array}$ & $\begin{array}{c}\text { Pre }(\mathbf{n}=525) \\
\mathbf{4 8 \%}\end{array}$ & $\begin{array}{c}\text { Post }(\mathbf{n}=\mathbf{3 6 5}) \\
\mathbf{3 3} \%\end{array}$ \\
\hline Self Efficacy & $4.18(0.71)$ & $4.25(0.77)$ & $3.96(0.82)$ & $4.07^{*}(0.72)$ \\
\hline Graduate School Interest & $3.81(0.96)$ & $3.79(0.96)$ & $3.64(0.90)$ & $3.80^{*}(0.85)$ \\
\hline Attitudes & $3.53(0.23)$ & $3.55(0.23)$ & $4.46(0.54)$ & $4.48(0.55)$ \\
\hline Research Skills & $3.05(1.03)$ & $3.60^{*}(0.92)$ & $3.05(1.04)$ & $3.84^{*}(0.86)$ \\
\hline Identity as Scientist & $2.85(1.06$ & $3.16^{*}(1.06)$ & $2.85(0.97)$ & $3.20^{*}(1.03)$ \\
\hline Sense of Belonging & $3.84(0.76)$ & $4.05^{*}(0.69)$ & Piloted in sample & Piloted in sample \\
\hline Mentoring & NA & $3.06(0.89)$ & N/A & $3.58(0.82)$ \\
\hline
\end{tabular}

In both cohort years of the Program, student survey outcomes indicated practical increases in all survey constructs, except graduate school interest, with statistically significant gains found in research skills and in identity as a CS researcher. For the inaugural year, self-efficacy and interest in graduate school increased significantly. Sense of belonging increased significantly in 2019-20, the first year this construct was measured. Type of workshop structure (weekend, term, academic year) was found to have no relationship to student outcomes. Overall, these findings indicate that the Program is successfully accomplishing the goals of building skills, creating community, and developing student motivation and confidence to pursue CS research. As of the 2020-21 academic year program cycle, exploreCSR requests that students opt-in to follow-up contact to repeat the post-survey six and twelve months after the academic year ends in order to evaluate if impacts persist.

\section{Qualitative Measurement Overview}

A semi-structured interview process was employed that followed the four evaluation criteria (Figure 1). The phenomenological qualitative research methodological approach was used to analyze data using Dedoose software. Additionally, ethnographic observations were conducted using the Classroom Observation Protocol for Undergraduate STEM (COPUS) programs. Volunteer participants received a $\$ 20$ gift card.

In 2019-20, interviews were conducted across seven institutions, interviewing a total of 28 students, all of whom were women. Forty-two percent were in their freshmen or sophomore years, 29\% from lower SES, and 29\% identified as AAHN women. In 2018-19, 23 students and 12 faculty were interviewed at 12 institutions. All of the students were women, $52 \%$ of whom identified as AAHN, 33\% were in their freshman or sophomore year, and 55\% were from lower SES. Faculty interviewed were majority female (84\%), $38 \%$ of whom identified as AAHN.

Overall themes show that the program goals were being attained with a strong theme of empowerment through a community of women. Students demonstrated that they learned to not internalize failure, developed grit, and improved their 
belief in their abilities as computer scientists. The workshops increased their motivation and commitment to pursuing graduate school and improved their attitudes about CS research. Participation in the workshops increased their professional, technical, and research skills, which brought them a sense of confidence. Seeing other women, in their peer cohorts and among their institutional graduate students and faculty, brought them a sense of community and belonging not available elsewhere. The students reported that they learned strategies for becoming more balanced in their work and personal lives. Two quotes, one from each program cohort, demonstrate these themes.

- "And now I see there's a bunch of women who not only are a part of the field [but] they're successful within the field. And that's really inspiring. And like I said before, I learned about the different routes you could take professionally within computing, and that really has opened up a wider field for me to choose from. Rather than just working for another company or something like that." - Camille (alias)

- "The [workshop] made me realize how much potential I do have. Because I was just kind of going with the flow, going [through] my classes not really putting myself out there, until [Dr. X] mentored me. And she was like, 'You should get involved. Do it. You're really going to like it.' And I was like....I was so iffy, not because I didn't want to, just because [of how] intimidating [it can be] to be in a room full of girls that are probably way ahead of me. But it made me realize that I do have a lot more to give than what I think I do. And if I think that [I can do this work], it will get me a lot further than what I realize." - Rosa (alias)

All institutions funded to execute IREs by exploreCSR engaged in vibrant community of practice discussions about the challenges and opportunities with creating effective programming for broadening CS research pathways to women, especially AAHN women. This faculty stakeholder community (created through periodic cohort meetings) was designed to catalyze discussions of what is working and why, and to drive formative program evaluation. These interactive discussions also served as a means of gathering input from the faculty stakeholders and promoted collective learning about what strategies are effective.

\section{What Worked Well}

The program evaluation indicates that the Program reach to undergraduate women is remarkable and unique. The Program is engaging a larger number of undergraduate women than other national programs, such as the NSF CISE REU program [25, 26]. Many participants are from lower SES, and are early in their academic careers. The percentages of AAHN women are substantial, with $36 \%$ in 2018-19 and 38\% in 2019-20. These descriptive counts indicate that the Program is making a substantial and unique contribution to efforts to broaden participation in CS research. The Program has substantially widened the recruiting door for women and for AAHN women by making these experiences locally available, accessible to entry-level students, and by accepting students based upon interest rather than perceived merit. Because students can remain home, they are able to continue employment and other personal commitments, thus offsetting barriers to participation in research programs at distant institutions. Interest-based recruiting versus merit- or accomplishment based, competitive recruiting additionally alleviates barriers related to science capital, such as obtaining a faculty reference. Table 2 below provides a synopsis of observed impactful features of exploreCSR-supported IREs, and may serve as a useful checklist for other institutions developing their own IREs.

Establishing a community of practice for faculty serving as workshop PIs is a cornerstone strategy. Just as students learn from peers and near-peer mentors, faculty learn from one another, and build institutional capacity to execute IRE workshops. We observed workshop outcomes to improve in second-year iterations. When examining institutional workshops that were funded in both cohort years (2018 and 2019), each program showed improved student outcomes in their second year of operation. These findings are encouraging because they suggest that providing multiple years of funding enables institutional learning as it provides faculty with the opportunity to iterate from their IRE planning and delivery experiences and to share their knowledge with the Program community.

\section{Table 2. IRE Core Features}

\begin{tabular}{|l|l|}
\hline Core Features of IREs & Effective Strategies \\
\hline $\begin{array}{l}\text { Community: Critical } \\
\text { Mass of Women }\end{array}$ & $\begin{array}{l}\text { Participation is interest based, not merit based; Local and } \\
\text { regional cohorts of women in CS; work across computing fields } \\
\text { and local institutions so women see themselves in research. }\end{array}$ \\
$\begin{array}{l}\text { Community: Create } \\
\text { Sense of Belonging }\end{array}$ & $\begin{array}{l}\text { Showcase women in CS research (faculty, industry) to share } \\
\text { personal journeys; Address topics that focus on issues facing } \\
\text { women and women of color: imposter syndrome, bias, } \\
\text { microaggressions, work/life balance. }\end{array}$ \\
\hline Skills and Confidence & $\begin{array}{l}\text { Hands-on research is bulk of the workshop content; Weekend } \\
\text { or semester-long engagement is as effective as academic year } \\
\text { workshops at building skills and developing confidence; Topical } \\
\text { foci to include: mindset and managing failure. }\end{array}$ \\
\hline Motivation & $\begin{array}{l}\text { Apply CS research for social good; Provide ways for women to } \\
\text { 'give back' directly through mentoring others (local community, } \\
\text { near peers, tiered mentoring); Faculty-student mentoring } \\
\text { should be personal and professional. }\end{array}$ \\
\hline $\begin{array}{l}\text { Faculty Learning } \\
\text { Community }\end{array}$ & $\begin{array}{l}\text { Convene faculty/PIs regularly to share tips and resources that } \\
\text { enable capacity building, across the workshops and within each } \\
\text { institution. }\end{array}$ \\
\hline
\end{tabular}

\section{Lessons Learned}

The most impactful IRE workshop features build a community of women at a variety of career stages, provide hands-on research opportunities, and discuss research in terms of personal experiences and motivations. From review of quantitative and qualitative measures (student surveys and interviews, workshop observations, and faculty discussions), we learned that students prefer direct experiences in research over formal faculty talks about research. While research talks are a necessary means of showcasing research topics and tangible 
career experiences, more time should be dedicated to hands-on student activities. Many faculty are inclined to use research talks to offer didactic displays of innovation and achievement, which has the unintended consequence of de-humanizing the research process. This type of talk can actually intimidate rather than inspire some students. As one student commented: "Getting to meet other students with the same passion as me (was most rewarding), and meeting students from my school too. But most importantly, I think it was not only hearing people talk about their success but also their struggle [sic] and failures. I think that is important to present because it shows that not everything goes smoothly or that everyone has this perfect life." Instead, researchers should showcase their work and their lives, sharing the challenges they have faced, and how they overcame these challenges. Both faculty or industry speakers should also be encouraged to discuss how their research translates to realworld impact, share their personal journey towards a CS research career, and provide advice about getting started. Panels should also be comprised of speakers who are representative of participating students.

Mentoring is a known feature of supporting students through their academic and professional pursuits. What warrants special attention for women in CS is the need for nearpeer support. Graduate student mentors provide a less intimidating and more relational dynamic. This, coupled with access to faculty who can advocate for students to participate in CS research engagement is a powerful tool in motivating undergraduate women to pursue graduate degrees and CS research careers. For example, women who are first-generation college students and/or from a lower SES background may not be aware of avenues for financial support, such as scholarships, fellowships, etc. Being made aware of and recommended for these opportunities by a faculty member can equip students with confidence and actionable career progress. Having access to women who share intersectional backgrounds is especially motivating for AAHN women [9]. These features offered together increase undergraduate women's science capital [1], that is their identification with CS research, relationships with CS researchers, and sense of belonging.

\section{Conclusion and Next Steps}

The objectives of exploreCSR are being met. The primary goals of the Program are to increase a sense of community, build technical and professional skills, develop confidence, and motivate students who identify as women and/or AAHN to engage in CS research pathways. The Program reaches a larger number and proportion of these students than comparable initiatives, and supports learning within and across funded institutions. Independently, all 29 workshops contributed to the development of community, among students and faculty champions of broadening participation in computing. Increases were observed across institutions, many significant, that demonstrate the intervention grew a sense of community among undergraduate women that built skills, confidence, and motivation to engage in CS research and graduate study. The evaluation model provides evidence that the Program is a core component within the ecosystem of broadening participation in computing initiatives due to its unique features.

This experience report contributes to the field in three ways. It demonstrates how to evaluate IREs across multiple workshop settings for alignment of indicators of success. It provides recommendations from the current literature and our operationalized experience for the known features that welcome and support women from all cultural backgrounds and encourages them to pursue CS research. The report provides support for the contention that IREs can be effective in different institutional contexts and with different structural approaches. And finally, it outlines the programmatic features that have been observed to be most impactful to women.

The most impactful features for women include the establishment of local communities with a critical mass of peers, and access to graduate students and faculty who share their intersectional identities $[10,31]$. Immersive engagement in research that can be applied to societal impact are core features meaningful to students who identify as women and/or AAHN [9], as well as personalized stories of overcoming. Additionally, mentoring for actionable career progress supports development of students' science capital.

Given the current context of a global pandemic, we all face challenges in building and sustaining our campus communities. We are optimistic that exploreCSR will discover new ways to support inclusive communities in CS research. Going forward, exploring features that work in virtual environments will be a major focus. Additionally, we will continue conducting research that addresses intersectional identities and capital as they impact persistence and motivation to pursue CS research pathways. Lagging indicators such as enrollment and degrees conferred will be monitored annually, as will specific academic and career outcomes of exploreCSR participants over time in order to gauge longitudinal impact. We also plan to implement quantitative evaluation for participating faculty to better understand the effect of the community of practice on future IRE implementation, as well as whether exploreCSR leads to additional funding, recognition, and opportunities for participating faculty. We invite colleges and universities to join us in offering IREs in their communities and in our collaborative efforts to understand and support diversity and inclusion for more equitable pathways into CS and research.

\section{REFERENCES}

[1] Louise Archer, Emily Dawson, Jen DeWitt, Amy Seakins, \& Billy Wong (2015) Science Capital: a conceptual, methodological, and empirical argument for extending Bourdieusian notions of capital beyond the arts. Journal of Research in Science Teaching, 52(7): 922-948. DOI: 10.1002/tea.21227.

[2] W. Aspray \& A. Bernat (2000). Recruitment and retention of underrepresented minority graduate students in computer science: Report of a workshop, March 4-5, 2000. Washington, DC: Computing Research Association.

[3] Lecia Barker (2009). Student and faculty perceptions of undergraduate research experiences in computing. ACM Transactions on Computing Education, 9,1, Article 5 (March 2009), 28 pages.

[4] a) Tracy Camp, W. Richards Adrion, Betsy Bizot, Susan Davidson, Mary Hall Susanne Hambrusch, Ellen Walker, \& Stuart Zweben. (2017). Generation CS: the growth of computer science. ACM Inroads 8, 2 (2017), 44-50.

[5] b) Tracy Camp, Christine Liebe, \& Michelle Slattery (2020). Applying NCWIT Protocol to Broaden Participation in Computing: A case study of CS@Mines. 
In Proceedings of the $51^{\text {st }}$ ACM Technical Symposium on Computer Science Education (SIGCSE '20). Association for Computing Machinery, New York, NY, USA, 528-534. DOI: 10.1145/3328778.3366958.

[6] E. Castilla \& S. Bernard (2010). The paradox of meritocracy in organizations. Administrative Science Quarterly, 55(4), 543-576. DOI:10.2307/41149515.

[7] L. V. Charleston, M. N. Lang, R. P. Adserias \& J. Jackson (2014) Intersectionality and STEM: The role of race and gender in the academic pursuits of African American women in STEM. Journal of Progressive Policy and Practice, 2(3), Fall 2014. http://caarpweb.org/wpcontent/uploads/2014/12/Charleston-Adserias-Lang-Jackson-2014.pdf.

[8] H. F. Hansen. (2005). Choosing Evaluation Models: a discussion on evaluation design. Evaluation, 11(4), 447-462. DOI: 10.1177/1356389005060265.

[9] A. Hodari, M. Ong, L. Ko, \& R. Kachchaf (2014). New enactments of mentoring and activism: US women of color in computing education and careers. Proceedings of the $10^{\text {th }}$ Annual Conference on International Computing Education Research, August 11-13, 2014, Glasgow, United Kingdom.

[10] K. Kim, A. Fann, \& K. Misa-Escalate (2011). Engaging women in computer science and engineering: Promising practices for promoting gender equity in undergraduate research experiences. ACM Transactions on Computing Education, 11(2), Article 8, (July 2011), 19 pages. DOI:101145/1993069.1993072.

[11] G. D. Kuh (2008). High Impact Practices: What They Are, Who Has Access to Them, and Why They Matter. Association for American Colleges \& Universities.

[12] S. Laursen, A. Hunter, E. Seymour, H. Thiry, \& G. Melton (2010) Undergraduate Research in the Sciences: Engaging Students in Real Science. San Francisco, CA: Jossey-Bass.

[13] K. Lewis, J. Stout, N. Finkelstein, S. Pollock, A. Miyake, G. Cohen \& T. Ito (2017). Fitting in to move forward: Belonging, gender and persistence in the physical sciences, technology, engineering and mathematics (pSTEM). Psychology of Women Quarterly, De. 2017, 41(4), 1-17. DOI: $10.1177 / 03616843117720186$.

[14] D. Lopatto (2007). Undergraduate research experiences support science career decisions and active learning. CBE- Life Sciences Education, 6, 297-306.

[15] R. Matzen, \& R. Alrifai (2012). Defining undergraduate research in computer science: A survey of computer science faculty. Journal of Computing Sciences in Colleges, 27, 31-37.

[16] S. Menzel, K. Siek, \& D. Crandall (2019). Hello Research! Developing an intensive research experience for undergraduate women. In Proceedings of the $50^{\text {th }}$ ACM Technical Symposium on Computer Science Education (SIGCSE '19), February 27- March 2, 2019, Minneapolis, MS, USA. DOI: $10.1145 / 3287324.3287493$.

[17] D. Michell, A. Szorenyi, K. Faulkner, \& C. Szabo (2017). Broadening participation not border protection: How universities can support women in computer science. Journal of Higher Education, Policy, and Management, $39(4), 406-422$

[18] A. Nyame-Mensah, B. Tamer, \& J. Stout (2015). Understanding How Summer Research Experiences Can Foster Diversity in Computing. Computing Research Association: Washington, DC. Available from http://cra.org/cerp/research-findings/ .

[19] M. Ong. (2011). Broadening Participation: the Status of Women of Color in Computer Science. Communications of the ACM, 54(7), July 2011. DOI:10/1145/1965724.1965737.

[20] Miranda Parker, Jason T. Black, Helen H. Hu, and Colleen M. Lewis. (2019) Exploring our privilege: Activities and discussions. In proceedings of the $50^{\text {th }}$ ACM Technical Symposium on Computer Science Education (SIGCSE '19). Association for Computing Machinery, New York, NY, USA 651-652. DOI: $10.1145 / 3287324.3287512$

[21] M. Q. Patton (2013). Utilization-focused evaluation checklist. Retrieved from https://wmich.edu/evaluation/checklists.
[22] J. Peckam, P. Stephenson, J. Herve, R. Hutt \& M. Encarnacao (2007). Increasing student retention in computer science through research programs for undergraduates. In Proceedings of the ACM Special Interest Group on Computer Science Education (SIGCSE-07), March, 2007, Covington, KY, USA.

[23] OurCS at Carnegie Mellon University. 2019. Available from http://www.cs.smu.edu/ourcs

[24] Miranda Parker, Jason Black, Helen Hu, \& Colleen Lewis (2019). Exploring our privilege: Activities and discussions. Proceedings of the $50^{\text {th }}$ ACM Technical Symposium on Computer Science Education (SIGCSE '19), February 27March 2, 2019, Minneapolis, MS, USA. DOI:10.1145/3287324.3287512.

[25] a) A. Rorrer (2016). An evaluation capacity building toolkit for principal investigators of undergraduate research experiences: A demonstration of transforming theory into practice. Evaluation and Program Planning, 55, 103111. DOI:10.1016/j.evalprogplan.2015.12.00.

[26] b) A. Rorrer, J. Allen, \& H. Zuo (2018). A national study of undergraduate research experiences in computing: Implications for culturally relevant pedagogy. In Proceedings of the $49^{\text {th }}$ ACM Technical Symposium on Computer Science Education (SIGCSE '18), February 21-24, 2018, Baltimore, MD, USA. DOI: $10.1145 / 3159450.3159510$.

[27] L. Sax, H.B. Zimmerman, J. M. Blaney, B. Toven-Lindsey \& K. Lehman (2017) Diversifying Computer Science Departments: How department chairs become change agents for women and underrepresented minority students. Journal of Women and Minorities in Science and Engineering, 23(2): 101-119.

[28] L. Sax, K. Lim, K. Lehman, \& L. Monje-Paulson (2018). Reversal of the Gender Gap: The biological sciences as a unique case within science, technology, engineering and mathematics (STEM). The Journal of Women and Minorities in Science and Engineering, 24(4): 291324.DOI:10.1615/jwomenminorscieneng.2018019995.

[29] Jane G. Stout \& Jennifer M. Blaney (2017). But it doesn't come naturally: How effort expenditure shapes the benefit of growth mindset on women's sense of intellectual belonging in computing. Computer Science Education 27, 3-4, 215 228.

[30] D. L. Stufflebeam (1983). The CIPP Model for Program Evaluation. In Evaluation Models. Evaluation in Education and Human Services, 6, Springer, Dordrecht. DOI:10.1007/978-94-009-6669-7_7 .

[31] B. Tamer \& J. Stout (2016). Understanding how research experiences for undergraduate students may foster diversity in the professorate. In Proceedings of the ACM Technical Symposium on Computer Science Education (SIGCSE '16), March 2-5, 2016, Memphis, TN, USA. DOI:10.1145/2839509.2844573.en Andler. 1979. Predicate path expressions. In Proceedings of the 6th. ACM SIGACT-SIGPLAN Symposium on Principles of Programming Languages (POPL '79). ACM Press, New York, NY, 226-236. DOI:https://doi.org/10.1145/567752.567774

[32] J. J. Thompson \& D. Jensen-Ryan (2018). Becoming a "Science Person": Faculty recognition and the development of cultural capital in the context of undergraduate biology research. CBE-Life Sciences Education, 17(4), November 16, 2018. DOI:10.1187/cbe.17-11-0229.

[33] S. F. Way, D. B. Larremore, \& A. Clauset (2016). Gender, productivity and prestige in Computer Science faculty hiring networks. Proceedings of the 2016 World Wide Web Conference (WWW), 1169-1179 (2016). arXiv:1602.00795.

[34] H. Wright \& B. Tamer (2019). Can sending first and second year computing students to technical conferences help retention? In Proceedings of the $50^{\text {th }}$ ACM Technical Symposium on Computer Science Education (SIGCSE '19), February 27- March 2, 2019, Minneapolis, MS, USA. DOI: $10.1145 / 3287324.3287349$

[35] S. Zweben \& B. Bizot (2019). The Taulbee Survey 2019. Computing Research Association, May 2019, 31(5). https://cra.org/wpcontent/uploads/2020/05/2019-Taulbee-Survey.pdf 